\title{
Development of an Orally Bioavailable Isoliquiritigenin Self-Nanoemulsifying Drug Delivery System to Effectively Treat Ovalbumin-Induced Asthma
}

This article was published in the following Dove Press journal:

International Journal of Nanomedicine

\author{
Mingzhuo Cao (ID \\ Mengling Zhan ${ }^{1,2}$ \\ Zheng Wang ${ }^{1,2}$ \\ Zeqian Wang ${ }^{1,2}$ \\ Xiu-Min $\mathrm{Li}^{3}$ \\ Mingsan Miao'
}

'Academy of Chinese Medical Sciences, Henan University of Chinese Medicine, Zhengzhou 450058, People's Republic of China; ${ }^{2}$ College of Pharmacy, Henan University of Chinese Medicine,

Zhengzhou 450058, People's Republic of China; ${ }^{3}$ Department of Microbiology and Immunology, and Otolaryngology, New York Medical College, Valhalla, NY I0595, USA
Correspondence: Xiu-Min Li Department of Microbiology and Immunology, and Otolaryngology, New York Medical College, Valhalla, NY I0595, USA

Email XiuMin_Li@NYMC.edu

\section{Mingsan Miao}

Academy of Chinese Medical Sciences, Henan University of Chinese Medicine, Zhengzhou 450058, People's Republic of China

Email miaomingsan@|26.com
Purpose: Isoliquiritigenin (ILQ), an important component of Anti-Asthma Herbal Medicine Intervention (ASHMI), had shown potent anti-asthma effect in vitro in our previous study. However, poor solubility and low bioavailability hindered in vivo application to treat asthma. This study was to develop a novel ILQ loaded self-nanoemulsifying drug delivery system (ILQ-SMEDDS) with enhanced bioavailability.

Methods: The optimized SMEDDS formulation was composed of ethyl oleate (oil phase), Tween 80 (surfactant) and PEG400 (co-surfactant) at a mass ratio of 3:6:1. The physiochemical properties of ILQ-SMEDDS, including drug content, globule size, zeta potential, scanning electron microscopy (SEM), Fourier transform infrared (FTIR) spectroscopy, were characterized. And the in vitro release profile, in situ intestinal absorption, in vivo pharmacokinetic parameters and the anti-asthma effect of ILQ suspension and ILQ-SMEDDS were evaluated.

Results: The ILQ-SMEDDS had an average globule size of $20.63 \pm 1.95 \mathrm{~nm}$ with a polydispersity index (PDI) of $0.11 \pm 0.03$, and its zeta potential was $-12.64 \pm 2.12 \mathrm{mV}$. The cumulative release rate of ILQ from ILQ-SMEDDS to the simulated gastrointestinal tract was significantly higher than that of free ILQ suspension. And area under curve with ILQ-SMEDDS was found to be 3.95 times higher than that of ILQ suspension indicating improved bioavailability by SMEDDS. Although ILQ-SMEDDS showed a slight less effective inhibitory effect on eotaxin-1 in human lung fibroblast (HFL-1) cells than free ILQ, in an ovalbumin-induced asthma model, ILQ-SMEDDS exhibited more efficacy than ILQ suspension in improving asthma-associated inflammation, including eosinophil production, ovalbumin-specific immunoglobulin E (OVA-sIgE), interleukin 4 (IL 4), interleukin 5 (IL 5) and interferon- $\gamma($ IFN- $\gamma)$. Even the low dose of ILQ-SMEDDS group $(10 \mathrm{mg} / \mathrm{kg})$ showed better anti-asthma effect than that of the ILQ suspension group $(20 \mathrm{mg} / \mathrm{kg})$.

Conclusion: Compared with ILQ suspension, ILQ-SMEDDS showed significantly improved bioavailability and anti-asthma effect, revealing its potential as a favorable pharmaceutical agent for treating asthma.

Keywords: isoliquiritigenin, self-nanoemulsifying drug delivery system, SMEDDS, ovalbumin-induced asthma, eotaxin-1, increased bioavailability

\section{Introduction}

Allergic asthma is a chronic inflammatory lung disease that has become a growing public health issue, currently affecting more than 300 million people worldwide. ${ }^{1}$ Although corticosteroids can effectively alleviate asthma symptoms, most patients 
will still have repeated attacks, and the long-term efficacy is poor, and their side effects of long-term use are a significant safety concern, particularly for both adults and children with severe asthma. ${ }^{2,3}$ There is an urgent need for safe and effective agents for treating asthma. Chinese herbal therapy (CHT), which has been used for thousands of years, has been suggested to have potential for treating allergies and asthma. ${ }^{4}$ Anti-asthma Herbal Medicine Intervention (ASHMI), a recently developed formula containing Ling-Zhi (Ganoderma lucidum), Ku-Shen (Sophora flavescens), and Gan-Cao (Glycyrrhiza uralensis), had been shown to significantly reduce $\mathrm{Th} 2$-mediated airway inflammation in a murine model of asthma and clinical studies. ${ }^{5-12}$ It was further found that Glycyrrhiza uralensis played an important role in the ASHMI formula, ${ }^{10}$ whose major chemical constituents are triterpenoids and flavonoids. Among the 10 compounds isolated and identified from Glycyrrhiza uralensis in our early study, we found that the flavonoids had potent eotaxin-1 inhibitory effect on HFL-1 cells in vitro, including liquiritigenin, isoliquiritigenin (ILQ, Figure 1A), 7,4'-dihydroxyflavone (7,4'-DHF, Figure 1B) and neoisoliquiritin. ${ }^{2,9,10,13}$ Moreover, ILQ and 7,4'-DHF were the two showing most effective anti-allergic asthma effect among these compounds. However, due to the extremely poor solubility and very low extraction yield $(0.15 \%)$ of $7,4^{\prime}-\mathrm{DHF},{ }^{2}$ its application in vivo was greatly restricted. Even if 7,4'-DHF showed a bit lower IC50 on eotaxin-1 inhibition than that of ILQ, we chose the ILQ as our model drug in the present study. ${ }^{10}$

Isoliquiritigenin, a flavonoid compound mainly found in the root of Glycyrrhiza uralensis, had potent antioxidant, ${ }^{14}$ anti-inflammatory, ${ }^{15-17}$ antitumor ${ }^{18}$ and antianaphylaxis ${ }^{10}$ effects. With a chalcone-type structure, ILQ is easily soluble in several organic solvents and dilute

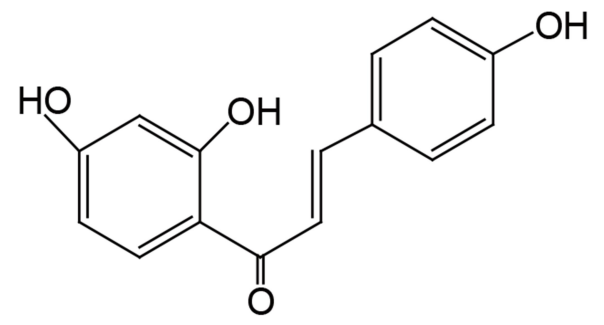

Isoliquiritigenin (ILQ) alkaline aqueous solution, but insoluble in water. ${ }^{19}$ Due to its poor solubility and quick elimination, ILQ has poor absorption in vivo and low bioavailability, which hinders its further in vivo application. ${ }^{20}$

In recent decades, plenty of efforts have been made to enhance the bioavailability of ILQ by using many nanotechnology-based oral or intravenous drug delivery systems, such as liposomes, ${ }^{21}$ lipid-polymer hybrid nanoparticles, ${ }^{22}$ mesoporous silica nanoparticles, ${ }^{23}$ nanostructured lipid carriers, ${ }^{18,24}$ hydrogels, ${ }^{25}$ polymeric micelles, ${ }^{26}$ inclusion complex. ${ }^{27}$ However, benefiting from its broad source of medical auxiliary materials, low cost and ease of fabrication, self-micro-emulsifying drug delivery system (SMEDDS) has received extensive attention. With good adaptability for oral administration, SMEDDS can spontaneously form oil-in-water globule with size less than $100 \mathrm{~nm}$ in the gastrointestinal tract (GIT) or with slight agitation at $37^{\circ} \mathrm{C}^{28}$ In addition, to improving the solubility and dissolution rate of waterinsoluble agents, SMEDDS also can enhance intestinal permeability and provide a greater interfacial absorption area, thereby improving the bioavailability of agents. ${ }^{29-31}$

In the interest of enhancing the solubility and in vivo availability of ILQ, we sought to design a formulation based on self-micro-emulsifying drug delivery system (SMEEDS) for oral administration of ILQ. In this study, we optimized the formulation of ILQ-SMEDDS and evaluated its appearance, mean globule size, zeta potential and morphology. Subsequently, we investigated the in vitro release profile, in situ intestinal absorptions and in vivo pharmacokinetic parameters of the ILQ-SMEDDS. Lastly, we tested its inhibition effect on eotaxin-1 in HFL-1 cells and evaluated the anti-asthma effect of ILQ-SMEDDS in an OVA-induced murine asthma model.<smiles>O=c1cc(-c2ccc(O)cc2)oc2cc(O)ccc12</smiles>

7,4'-dihydroxyflavone (7,4'-DHF) B

Figure I The structure of isoliquiritigenin (ILQ, (A)) and 7,4'-dihydroxyflavone (7,4'-DHF, (B)). 


\section{Experimental Section \\ Material and Cells}

Materials

Isoliquiritigenin (ILQ, 98.0\%) was purchased from Herb Purify Co. (Chengdu, China). Ethyl oleate (EO), 1,3-propanediol, castor oil acetanilide, urethane and phenol red were bought from Aladdin (Shanghai, China). Tween 80 (for cells culture), ovalbumin (V and II grade), (3-(4,5Dimethylthiazol-2-yl)-2,5-Diphenyltetrazolium Bromide) MTT, and $\mathrm{Al}(\mathrm{OH})_{3}$ gels were obtained from SigmaAldrich (Shanghai, China). PEG 400 was obtained from Yipusheng Pharmaceutical Co (Jiangxi, China). Ham's F12K medium was obtained from Bosterbio (Boster, Wuhan, China). Fetal bovine serum (FBS) was bought from Gibco (Gibco, Australia).

\section{Cell Culture}

Human lung fibroblast cells (HFL-1 cells, ATCC® CCL153 ${ }^{\mathrm{TM}}$ ) were bought from American Type Culture Collection (Rockville, MD, USA). HFL-1 cells were grown in F-12K medium containing $10 \%$ fetal bovine serum (Gibco, Australia) and 1\% penicillin-streptomycin solution at $37^{\circ} \mathrm{C}$ in a $5 \% \mathrm{CO}_{2}$ humidified incubator. And cells were sub-cultured by digesting cells with $0.5 \%$ trypsin-EDTA. The medium was changed every 3 days.

\section{Animals}

All the animal studies were approved by the Animal Care and Use Committee (Approval No. DWLL201903312) of Henan University of Chinese Medicine and were performed in strict accordance with the NIH guidelines for the care and use of laboratory animals.

Female Sprague Dawley (SD) rats $(220 \pm 20 \mathrm{~g})$, female Kunming mice (8-10 weeks old) and female BALB/c mice (6-8 weeks old) were obtained from Shandong Laboratory Animal Center (Peng-Yue Laboratory Animals, Jinan, China). All mice were housed at $22^{\circ} \mathrm{C}$ in cages within laminar airflow hoods in a specific pathogen-free room with a 12-h light/12-h dark cycle and fed autoclaved chow and water ad libitum. All the animals were fasted overnight before experiment with free access to water.

\section{Preparation and Characterization of ILQ- SMEDDS HPLC Method}

ILQ was assayed by reversed phase HPLC on a Poroshell HPH-C ${ }_{18}$ column $(250 \times 4.6 \mathrm{~mm}, 4 \mu \mathrm{m}$, Agilent Co. Ltd., USA). The HPLC was performed on a waters e2695 system consisting of alliance Quat gradient pump, 2998 diode array detector and empower 3 chromatographic software. The HPLC method for analyzing ILQ was established as previously reported. ${ }^{32}$ The detailed conditions were as follows: acetonitrile-water mixture $(60 / 40, \mathrm{v} / \mathrm{v})$ was used as mobile phase, with column temperature at $30^{\circ} \mathrm{C}$, wavelength at $372 \mathrm{~nm}$, and flow rate $1.0 \mathrm{~mL} / \mathrm{min}$.

\section{Solubility Studies}

The solubility of ILQ in various solvents, including oils, surfactants and co-surfactants was measured using methods reported in an early study with slight modifications. ${ }^{33}$ Excess ILQ was added to $2 \mathrm{~mL}$ of various solvents, respectively. Then, the mixtures were sonicated for 10 min, and shaken at $100 \mathrm{rpm}$ for $24 \mathrm{~h}$ on an oscillator (Agene Laboratory Equipment Co., Ltd. Shanghai, China) at $37^{\circ} \mathrm{C}$. After that, the mixture was centrifuged at $8000 \mathrm{rpm}$ for $30 \mathrm{~min}$ to remove the precipitate. The supernatants were diluted with acetonitrile. The solubility of ILQ in each solvent was analyzed using HPLC.

\section{Optimization, Preparation and Characterization of the ILQ-SMEDDS}

SMEDDS formulations were prepared using oils, surfactants, and co-surfactants with good ILQ solubility. The components were mixed in designed ratios to obtain a homogeneous mixture. The transparent mixtures were titrated with water dropwise under gentle agitation (1:100 dilution). Each formulation was evaluated for the appearance and self-emulsifying ability. And the globule size, zeta potential of optimized SMEDDS was measured by using a Nano Brook 90Plus PALS sizer (Brookhaven Instruments Corporation, Holtsville, NY, USA) at $25^{\circ} \mathrm{C}$.

The ILQ-SMEDDS was prepared according to a previously reported method with some modifications. ${ }^{33}$ EO (300.9 mg), tween 80 (600.5 mg) and PEG 400 (103.5 mg) were mixed well, and sonicated for $10 \mathrm{~min}$ to obtain a clear and transparent liquid. Then, the excess ILQ was added, followed by sonication for $10 \mathrm{~min}$, and oscillating at $37^{\circ} \mathrm{C}$ at $100 \mathrm{rpm}$ over-night. Finally, ILQ-SMEDDS was centrifuged at $8000 \mathrm{rpm}$ for $30 \mathrm{~min}$ to remove the prescription before use. The supernatant was taken and the solubility of ILQ in SMEDDS was determined by HPLC.

A 2-level factorial design was used to determine the optimal formulation by evaluating the impact of the two factors (mass percentage of oil $\mathrm{X}_{1}$, blend ratios of surfactant to co-surfactants $\left.\mathrm{X}_{2}\right)$ on the globule size $\left(\mathrm{Y}_{1}\right)$ and drug content $\left(\mathrm{Y}_{2}\right)$. The percentage of oil phase $\left(\mathrm{X}_{1}\right)$ varied from 
$10 \%$ to $30 \%$ and the blend ratios of surfactant to cosurfactants $\left(\mathrm{Km}, \mathrm{X}_{2}\right)$ were in the range of $1: 1$ to $7: 1$. All ILQ-SMEDDSs were diluted 10 times, and the globule size, $\zeta$ potential and drug content were measured. The Sklearn library function of Python language was used to statistically analyze the response results to determine the optimal formulation with the maximum drug content and the small globule size.

The morphology of optimized ILQ-SMEDDS was obtained by transmission scanning electron microscope (TEM-1400, Tokyo, Japan) after staining with 2\% phosphato-tungstic acid (PTA). The IR spectra of ILQSMEDDS were recorded on the Fourier-transform infrared spectrometer (FT-IR) (Spectrum 100, Platinum Elmer, Waltham, MA, USA) by using a potassium bromide pressed-disk method.

\section{Stability of ILQ-SMEDDS}

The stability of ILQ-SMEDDS was performed at various storage times and $\mathrm{pH}$, and the variations in the size, polydispersity index (PDI), and $\zeta$ potential were investigated. The emulsion samples were kept in vials and were stored at $40^{\circ} \mathrm{C}$ or $4^{\circ} \mathrm{C}$ for 3 months. At a scheduled time $(0,1$ and 3 months), they were diluted with 10 times ultrapure water, and then the globule sizes, PDIs and $\zeta$ potentials were measured.

To evaluate whether it would be destroyed in the gastrointestinal tract, newly prepared ILQ-SMEDDS was diluted at predetermined extent with simulated gastric (pH 1.2 hydrochloric acid) and intestinal ( $\mathrm{pH} 6.8$ PBS) fluid, and their globule sizes, PDIs and $\zeta$ potentials were measured.

\section{In vitro Release Profile}

According to the Chinese Pharmacopoeia (2015), in vitro ILQ release profiles of ILQ suspension (or ILQ + SMEDDS) and ILQ-SMEDDS in the two media were measured by dialysis-diffusion method with slight modification. ${ }^{34}$ ILQ suspension (5mg ILQ in $2 \mathrm{~mL}$ of $2 \%$ tween 80 medium) and ILQ-SMEDDS ( $2 \mathrm{~mL}$ micro-emulsion, containing equivalent ILQ amount) were obtained in a dialysate bag with a molecular weight cut-off of 5000 Da. Then, they were placed in $250 \mathrm{~mL}$ of release media $(\mathrm{pH} 1.2 \mathrm{HCl}$ for the first $2 \mathrm{~h}$ and $\mathrm{pH} 6.8 \mathrm{PBS}$ for the rest $22 \mathrm{~h}$, containing $1 \%$ Tween 80 ) under a temperature of $37^{\circ}$ $\mathrm{C}$ and an oscillation of $100 \mathrm{rpm}$. At $0,0.25,0.5,0.75,1,2$, $4,8,12,16$ and $24 \mathrm{~h}$, respectively, dialysates ( $2 \mathrm{~mL}$ each) were taken and rapidly replenished with equal volume and type of fresh media. The content of ILQ in the dialysate was measured by HPLC, and the hemolytic toxicity of ILQ-SMEDDS was also investigated (Hemolytic toxicity).

\section{Eotaxin- I/CCLI I Inhibition Assay}

Eotaxin-1/CCL11 inhibitory effect of ILQ or ILQSMEDDS at various concentrations were tested as previously described. ${ }^{35}$ HFL-1 cells were plated into 24 -well plates at a density of $1 \times 10^{5}$ cells per well and cultured for $24 \mathrm{~h}$. After washing the cells with pre-warmed phosphatebuffered saline (PBS), various concentrations of ILQSMEDDS or ILQ (dissolved in DMSO, the final DMSO concentration less than 2\%o) were added to the cells and incubated for 72 hours. Medium alone served as the control. The supernatant was then collected and its eotaxin-1 level was measured using a qualitative enzyme-linked immunosorbent assay (ELISA, BD Biosciences, San Diego, CA, USA) according to the manufacturer's instructions. The absorbance was read at 450nm using a microplate reader (SpectraMax i3, Molecule Device Inc., USA). Eotaxin-1 (Pharmingen, Ca\#555175) Inhibition was calculated relative to the control according to the following equation.

$$
\text { Eotaxin }-1 \text { Inhibition } \%=\frac{O D_{\text {control }}-O D_{I L Q}}{O D_{\text {control }}} \times 100 \%
$$

Cell viability was measured by MTT assay as previously described. Briefly, HFL- 1 cells $\left(1 \times 10^{4}\right.$ cell per well) were seeded in 96-well plates and treated with various concentrations of ILQ-SMEDDS or ILQ. After 3 days, MTT stock solution was added to produce dark blue formazan crystals, and absorbance was read at $570 \mathrm{~nm}$.

\section{Absorption in situ, Pharmacodynamic and Pharmacokinetic in vivo Studies Intestinal Absorption in situ}

The in situ perfusion model in rats was used to study the intestinal absorption of ILQ-SMEDDS, and it was performed in the distal jejunum segment according to the references with a slight modification. ${ }^{36,37}$ In detail, each rat was anesthetized by intraperitoneal injection of $20 \%$ urethane (at a dose of $5 \mathrm{~mL} / \mathrm{kg}$ ), restricted to the supine position and kept at its normal body temperature using infrared lamps. Upon confirmation of the loss of pain reflex, its abdomen was opened with a midline longitudinal incision about $3 \mathrm{~cm}$ long. Then distal jejunum was intubated 
immediately with two glass tubes $(3.5 \mathrm{~mm}$, O.D.) and ligated with surgical silk suture. The selected intestinal segment was gently rinsed with pre-warmed PBS to remove faecal residues and debris, then attached to the perfusion assembly consisted of a peristaltic pump (L100-1F/DG-2, Baoding Longer Precision Pump Co., Ltd., China). One hundred milliliters of ILQ-SMEDDS or ILQ suspension with an initial ILQ concentration of $200 \mu \mathrm{g} / \mathrm{mL}$ (containing $20 \mu \mathrm{g} / \mathrm{mL}$ of phenol red) was perfused through intestinal wall at a flow rate of $6 \mathrm{~mL} / \mathrm{min}$ for $10 \mathrm{~min}$. Then, the flow rate was adjusted to $3 \mathrm{~mL} / \mathrm{min}$, and the solution volume was recorded as the 0 min volume. Each perfusion experiment lasted for $2 \mathrm{~h}$ and samples were collected at predetermined time intervals of $15 \min (0,15,30,45,60,75,90,105,120$ $\mathrm{min})$. At the end of the experiment, the radius and length of the perfused intestinal and the remaining of the amount of ILQ in each sample were measured. The absorption percentage (AP) for ILQ-SMEDDS or ILQ-Suspension, the absorption rate constant $\left(\mathrm{K}_{\mathrm{a}}, \mathrm{min}^{-1}\right)$, and the apparent permeability coefficient $\left(\mathrm{P}_{\mathrm{app}}, \mathrm{cm}^{2} \cdot \mathrm{min}^{-1}\right)$ and the enhancement ratio (ER) were calculated by the following formulas:

$$
\begin{gathered}
\mathrm{AP}=\frac{\mathrm{C}_{0} V_{0}-C_{t} V_{t}}{\mathrm{C}_{0} V_{0}} \times 100 \% \\
\ln \mathrm{X}_{\mathrm{t}}=\ln \mathrm{X}_{0}-\mathrm{K}_{\mathrm{a}} \times \mathrm{t} \\
\mathrm{P}_{\mathrm{app}}=\mathrm{K}_{\mathrm{a}} / \mathrm{A} \\
\mathrm{ER}=\frac{\mathrm{P}_{\text {app }} \text { of } \mathrm{ILQ}-\mathrm{SMEDDS}}{\mathrm{P}_{\mathrm{app}} \text { of } \mathrm{ILQ}-\text { Suspension }} \times 100 \%
\end{gathered}
$$

In which $\mathrm{C}_{0}$ (or $\mathrm{C}_{\mathrm{t}}$ ) and $\mathrm{V}_{0}$ were the concentration and volume of ILQ suspension (or ILQ-SMEDDS) in perfusate at 0 (or 2) h, respectively. $X_{t}$ and $X_{0}$ indicated the amounts of ILQ in the perfusion fluid at $\mathrm{t} h$ and $0 \mathrm{~h}$, respectively. A $\left(\mathrm{cm}^{2}\right)$ was the surface area of the intestinal segment perfused (Length $\times$ intestinal diameter).

\section{Pharmacokinetic Studies}

After one week of acclimation, 60 female Kunming mice were randomly divided into two groups. They were fasted for $12 \mathrm{~h}$ prior to the experiment. Raw ILQ suspension (in PBS containing $1 \%$ tween 80 ) and ILQ-SMEDDS (at an equivalent dose of ILQ) were orally administered to mice at the dose of $35 \mathrm{mg} / \mathrm{kg}$. $0.5 \mathrm{~mL}$ of blood samples were collected from the retro-orbital plexus with capillaries at predesigned time points $(0,0.25,0.5,0.75,1,1.5,2,4,8$, $12 \mathrm{~h}, 24 \mathrm{~h}$ ) after administration. Plasma was obtained by centrifuging the blood at $3000 \mathrm{rpm}$ for $15 \mathrm{~min}$ and was stored at $-80^{\circ} \mathrm{C}$ until further analysis by HPLC. Two hundred microliters of plasma sample was mixed with $20 \mu \mathrm{L}$ of acetanilide ( $50 \mu \mathrm{g} / \mathrm{mL}$, internal standard), then they were deproteinized with $600 \mu \mathrm{L}$ of acetonitrile containing $30 \mu \mathrm{L}$ of hydrochloric acid at $45^{\circ} \mathrm{C}$ for $15 \mathrm{~min}$. Then, the mixture was centrifuged at $12,000 \mathrm{rpm}$ for $15 \mathrm{~min}$. The supernatant was transferred into a $1.5 \mathrm{~mL}$ microtubes and was dried by a concentrator (Eppendorf, Germany) at room temperature. The samples were dissolved in mobile phase and further analyzed by HPLC as described in HPLC Method.

The main pharmacokinetic parameters, including Lambda_z $\left(\mathrm{h}^{-1}\right.$, first-order terminal elimination rate constant), $T_{\max }$ (h, time to reach the maximum plasma concentration), $\quad \mathrm{C}_{\max }\left(\mu \mathrm{g} \cdot \mathrm{mL}^{-1}, \quad\right.$ maximum plasma concentration), $\mathrm{AUC}_{0-12}\left(\mu \mathrm{g} \cdot \mathrm{mL}^{-1} \cdot \mathrm{h}\right.$, area under the plasma concentration-time curve), $\mathrm{Vz} / \mathrm{F}\left(\mathrm{L} \cdot \mathrm{kg}^{-1}\right.$, apparent volume of distribution), and $t_{1 / 2}$ ( $h$, half-life), were analyzed by the PKSolver 2.0 software (an add-in program for pharmacokinetic analysis in Microsoft excel) using a noncompartmental analysis.

\section{Establishment of Ovalbumin-Induced Asthma Model}

The OVA-induced asthma model was established using a previously reported method with minor modification. ${ }^{8,38,39}$ The $\mathrm{BALB} / \mathrm{c}$ mice were randomly divided into six groups $(n=6)$ as follows: Negative control group, Sham group, ILQ treatment group (twice $10 \mathrm{mg} / \mathrm{kg} /$ day), ILQ-SMEDDS treatment groups (low dose, twice $5 \mathrm{mg} / \mathrm{kg} /$ day; and high dose, twice $10 \mathrm{mg} / \mathrm{kg} /$ day), Dexamethasone treatment group (DEX, twice $0.25 \mathrm{mg} / \mathrm{kg} / \mathrm{day}$ ). Except for naïve group, BALB/c mice were sensitized by intraperitoneal (i.p.) injections of $100 \mu \mathrm{g}$ OVA (grade V) adsorbed to $2 \mathrm{mg}$ Alum in $200 \mu \mathrm{L}$ PBS on the 0th, 7th and 14th days (Figure S3). Then they were challenged intratracheally (i.t.) with $100 \mu \mathrm{g}$ OVA (II grade) in $100 \mu \mathrm{L}$ PBS on days of 21th, 28th, 35th, 63th and 64th (2 consecutive challenges, for a total of 5 i.t. challenges). All mice were intragastrical treated for 4 weeks after the day of 3rd challenge. The Naïve group was injected or treated with an equal volume of PBS.

\section{Pharmacodynamic Effect Assessment}

General morphological observation, OVA-sIgE in serum, inflammatory cell counts and IL-4, IL-5 and IFN- $\gamma$ cytokines in bronchoalveolar lavage fluid (BALF), and histopathology analysis of the lungs were used to assess pharmacodynamic effect of ILQ-SMEDDS. 
OVA-Specific-IgE (OVA-sIgE, Pharmingen, BD Biosciences, USA) Detection in Serum. Blood was collected at 62th and 66th. OVA-sIgE levels were measured by ELISA as previously reported. ${ }^{40}$

\section{Cell Counts and Cytokines in BALF}

Mice underwent bronchoalveolar lavage with 1-mL PBS by tracheal intubation. BALF recovery was about $50-65 \%$. BALF was centrifuged at $1,200 \mathrm{rpm}$ for $15 \mathrm{~min}$ at $4^{\circ} \mathrm{C}$. The supernatant was collected for cytokine analysis. Total cells were counted using a cell counter (Count star IC 1000, Shanghai, China). The cells were stained with Wright-Giemsa stain to determine cytologic classification. The expression levels of IL-4 (Cat\#555232), IL-5 (Cat\#555236) and IFN- $\gamma$ (Cat\#555138) were determined by ELISA according to the manufacturer's instructions.

\section{Histopathology Analysis}

After obtaining BALF, lung tissues were fixed with $4 \%$ paraformaldehyde, then dehydrated and embedded in paraffin. Embedded tissue samples were sectioned in $5 \mu \mathrm{m}$ thick using a Leica RM2235 microtome (Leica, Nussloch, Germany) and stained with hematoxylin and eosin (H\&E).

\section{Statistical Analysis}

All data are represented as mean \pm standard deviation (SD). All statistical analyses were performed using GraphPad Prism 7 software (GraphPad Software, Inc, La Jolla, CA). Statistical significance was analyzed by unpaired $t$-test (Mann Whitney test), with $\mathrm{p}$, smaller than 0.05 considered statistically significant.

\section{Results and Discussion Preparation and Characterization of Optimized ILQ-SMEDDS}

First, the composition of the initial formulation was obtained by screening high ILQ solubility surfactants, cosurfactants and oil phase excipients. ${ }^{41,42}$ The solubility of
ILQ at $25^{\circ} \mathrm{C}$ in various solvents is shown in Table 1 . Amongst the oils screened, castor oil (CO, 28.80 \pm 1.28 $\mathrm{mg} / \mathrm{g}$ ) and ethyl oleate (EO, $10.03 \pm 0.75 \mathrm{mg} / \mathrm{g}$ ) showed much better solubility than oleic acid $(2.03 \pm 0.56 \mathrm{mg} / \mathrm{g})$. Although castor oil showed better solubility than ethyl oleate, it was difficult to be emulsified, and the globule sizes were more than $100 \mathrm{~nm}$ in all SMEDDS prescriptions with castor oil. So, ethyl oleate was chosen as the oil phase. Highest solubility of ILQ was found in Tween 80 $(129.5 \pm 1.36 \mathrm{mg} / \mathrm{g})$ and it showed better capacity to emulsify ethyl oleate with a maximum transmittance. As we all know, alcoholic co-surfactants can improve the emulsification efficiency of surfactants because it further reduces the interfacial tension by improving the permeability of the oil phase in the non-polar area of the surfactant. $^{33}$ Except for glycerin, other cosurfactants exhibited excellent solubility, such as PEG400 (123.8 \pm $1.89 \mathrm{mg} / \mathrm{g})$, ethyl alcohol $(119.86 \pm 2.19 \mathrm{mg} / \mathrm{g})$ and $1.2-$ propanediol $(120.7 \pm 2.48 \mathrm{mg} / \mathrm{g})$. Compared with co-surfactants such as glycerol and ethanol, PEG400 has a longer $\mathrm{CH}_{2} \mathrm{OH}$ chain length, which helps the formulation to have a better transparent appearance and stability. Tween 80 and PEG400 are common oral pharmaceutical excipients, and both have very wide oral safety windows. ${ }^{43}$ Therefore, EO was selected as the oil phase, Tween 80 as the surfactant, and PEG400 as the cosurfactant.

In the formulation screening, the mass percentage of oil and $\mathrm{Km}$ value had a great impact on the globule size, drug load and stability of self-nanoemulsion. ${ }^{30,44}$ It was very important to optimize the proportion of excipients in the blank SMEDDS, so as to avoid precipitation and phase separation during dilution in GIT. ${ }^{34}$ The results (Figure S1) showed that when the mass ratio of oil phase was between $10 \%$ and $30 \%$, almost all the blank SMEDDS (10× dilution) was in a good state with a self-emulsifying time less than $2 \mathrm{~min}$. And their compositions, globule sizes, PDI, and zeta potentials are summarized in Table 2. The 2-level factorial design was applied to obtain the optimal formulation of ILQ-SMEDDS, and Figure 2

Table I Solubility of ILQ in Different Excipients

\begin{tabular}{|l|l|l|l|}
\hline Excipients & Solubility $\mathbf{~ m g / g}$ & Excipients & Solubility $\mathbf{~ m g / g}$ \\
\hline Oleic acid & $2.03 \pm 0.56$ & PEG-400 & $123.8 \pm 1.89$ \\
Ethyl oleate & $10.03 \pm 0.75$ & I.2-propanediol & $120.7 \pm 2.48$ \\
Castor oil & $28.80 \pm 1.28$ & Glycerin & $10.08 \pm 0.74$ \\
Tween 80 & $129.5 \pm 1.36$ & Ethyl alcohol & $119.86 \pm 2.19$ \\
Poloxamer-188 & $0.23 \pm 0.08$ & TPGS & $0.45 \pm 0.09$ \\
\hline
\end{tabular}


Table 2 Composition and Observed Responses from Randomized Runs in Formulation Screening

\begin{tabular}{|c|c|c|c|c|c|c|}
\hline \multirow{2}{*}{\multicolumn{2}{|c|}{$\begin{array}{l}\text { Composition } \\
(\%, \mathrm{~m} / \mathrm{m}) \\
\text { EO: Tween 80: } \\
\text { PEG400 }\end{array}$}} & \multicolumn{5}{|c|}{100 Times Dilution } \\
\hline & & \multirow{2}{*}{$\begin{array}{l}\text { Size(nm) } \\
12.0 \pm 0.17\end{array}$} & \multirow{2}{*}{$\begin{array}{l}\text { PDI } \\
0.09 \pm 0.01\end{array}$} & \multirow{2}{*}{$\begin{array}{c}\zeta \text { Potential } \\
-6.61 \pm 0.69\end{array}$} & \multirow{2}{*}{$\begin{array}{l}\text { Emulsification Time } \\
<\text { I min }\end{array}$} & \multirow{2}{*}{$\begin{array}{l}\text { Appearance } \\
\text { Transparent }\end{array}$} \\
\hline $\mathrm{FI}$ & $1: 6: 3$ & & & & & \\
\hline F2 & 2:7:1 & $77.59 \pm 1.58$ & $0.28 \pm 0.01$ & $-13.40 \pm 1.26$ & $<1$ min & Transparent \\
\hline F3 & $2: 5: 3$ & $15.77 \pm 0.74$ & $0.18 \pm 0.05$ & $-10.55 \pm 2.12$ & $<1 \min$ & Light blue \\
\hline F4 & $3: 5: 2$ & $21.14 \pm 0.48$ & $0.12 \pm 0.02$ & $-10.06 \pm 1.32$ & $<1 \min$ & Blue \\
\hline F5 & $3: 4: 3$ & $86.64 \pm 1.98$ & $0.30 \pm 0.01$ & $-5.98 \pm 1.75$ & $<2 \min$ & Light blue \\
\hline F6 & $3: 6: 1$ & $19.81 \pm 0.21$ & $0.10 \pm 0.01$ & $-11.64 \pm 0.46$ & $<1$ min & Blue \\
\hline F7 & $3: 7: 7$ & $15.45 \pm 0.09$ & $0.12 \pm 0.01$ & $-8.49 \pm 0.86$ & $<\mathrm{I} \min$ & Light blue \\
\hline F8 & $6: 14: 7$ & $17.01 \pm 0.29$ & $0.12 \pm 0.01$ & $-9.16 \pm 1.65$ & $<3 \min$ & white-blue \\
\hline F9 & $9: 21: 7$ & $|8.0| \pm 0.56$ & $0.12 \pm 0.01$ & $-9.74 \pm 0.92$ & $<1$ min & Light blue \\
\hline
\end{tabular}

shows the three-dimensional response results of the two factors (oil phase mass percentage and $\mathrm{Km}$ value) on the globule size $\left(\mathrm{Y}_{1}\right)$ and drug content $\left(\mathrm{Y}_{2}\right)$ in the formulations after drug loading. The results of the regression analysis of the responses are summarized in Table 3, the statistical models of $Y_{1}$ and $Y_{2}$ responses were fitted to linear, quadratic, respectively. Substituting the regression coefficients, the model equations could be derived, where the levels of factors and responses involved are as follows:

$$
\begin{aligned}
& \mathrm{Y}_{1}=2054 \mathrm{X}_{1}^{2}-176 \mathrm{X}_{1} \mathrm{X}_{2}+5.3 \mathrm{X}_{2}^{2}-255 \mathrm{X}_{1}+1.38 \mathrm{X}_{2}+26.4 \\
& \mathrm{Y}_{2}=80.66 \mathrm{X}_{1}+7.03 \mathrm{X}_{2}+12.40
\end{aligned}
$$

It could be seen from the $Y_{1}$ equation that there was a strong interaction between the oil mass percentage $\left(\mathrm{X}_{1}\right)$ and the $\mathrm{Km}$ value $\left(\mathrm{X}_{2}\right)$. When $\mathrm{X}_{1}$ was small and $\mathrm{Km}$ was also small, then a smaller globule size can be obtained. However, when $\mathrm{X}_{1}$ became larger, to obtain a smaller globule size, the $\mathrm{Km}$ value should also be a bit larger. When $X_{1}$ and $X_{2}$ took the minimum value of 0.1 and 2, a smaller globule size of $10.2 \mathrm{~nm}$ (actual $12.04 \mathrm{~nm}$ ) can be obtained. And when $\mathrm{X}_{1}$ and $\mathrm{X}_{2}$ took the maximum value of 0.3 and 6 , a smaller globule size of $17.04 \mathrm{~nm}$ (actual $21.84 \mathrm{~nm}$ ) could also be obtained. While the $\mathrm{Y}_{2}$ equation indicated that the drug content had a positive correlation with the oil mass percentage $\left(\mathrm{X}_{1}\right)$ and $\mathrm{Km}$ value $\left(\mathrm{X}_{2}\right)$. Therefore, when both $X_{1}$ and $X_{2}$ took the maximum value of 0.3 and 6 , a larger drug content of $78.78 \mathrm{mg} / \mathrm{mL}$ (actual $78.11 \mathrm{mg} / \mathrm{mL}$ ) could be obtained. In addition, in some formulation, it was found that as the drug content increased, it caused a sharp increase in globule size (more than 200nm, Table S1). In consideration of a small globule size, a large drug load and good stability of ILQSMEDDS, the final ratio in the formulation was determined as EO:Tween 80:PEG400 $=3: 6: 1$. After diluted
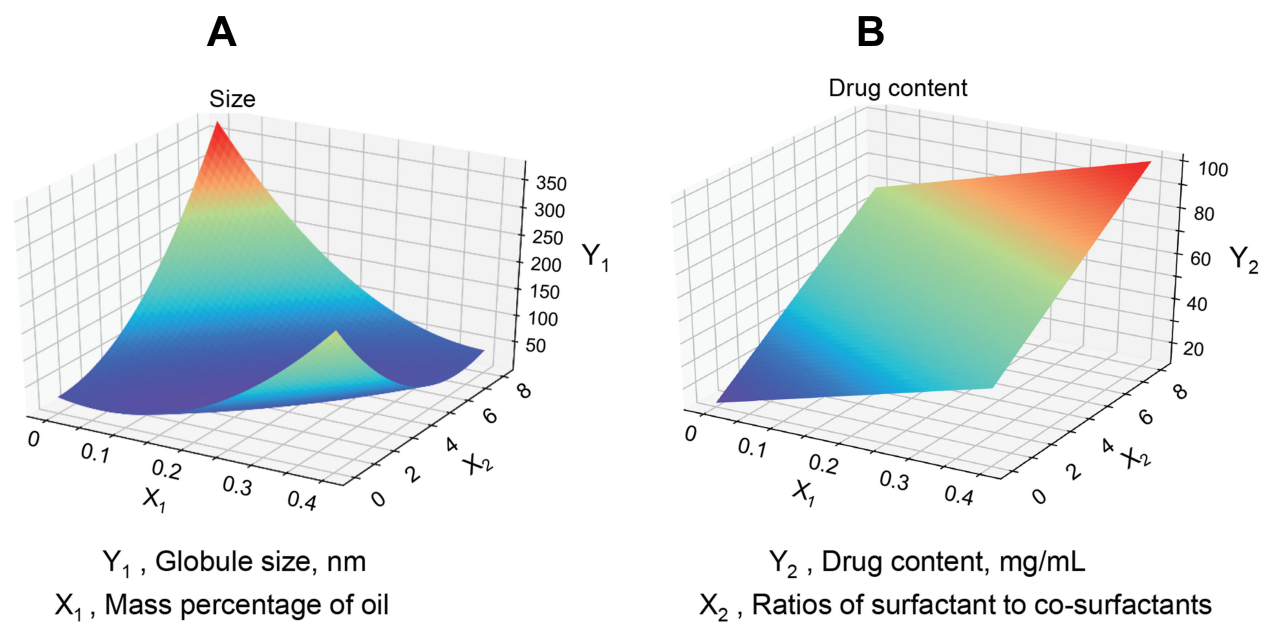

Figure 2 The three-dimensional response results of the two factors on the globule size $\left((\mathbf{A}), Y_{1}\right)$ and drug content $\left((\mathbf{B})\right.$, $\left.Y_{2}\right)$ after drug loading are shown. $X_{1}$ : Oil phase mass percentage, $X_{2}: K m$ value (Ratios of surfactant to co-surfactants). 
Table 3 Summary of the Results of Regression Analysis for the Responses

\begin{tabular}{|l|l|l|l|l|}
\hline Size $(\mathbf{n m})$ & Models & Mean Square Error & $\mathbf{R}^{\mathbf{2}}$ Score & Remark \\
\hline Globule size $\left(\mathrm{nm} ; \mathrm{Y}_{1}\right)$ & Linear & 627.31 & -4.44 & - \\
& Quadratic & 64.14 & 0.905 & Suggest \\
\hline Drug content & Linear & 18.74 & 0.91 & Suggest \\
$\left(\mu \mathrm{g} / \mathrm{mL} ; \mathrm{Y}_{2}\right)$ & Quadratic & 16.83 & 0.93 & - \\
\hline
\end{tabular}

100 times with water, it could form fine oil-in-water nanoemulsion, which was clear blue opalescence (Figure 3A). And the newly prepared ILQ-SMEDDS exhibited a clear yellow and transparent appearance (Figures 3A and $\underline{\mathrm{S} 2}$ ). Furthermore, there were some differences in appearance between ILQ-SMEDDS and their physical mixture (as shown in Figure S2). On their FTIR spectra, the characteristic absorption peaks (Figure 3B) at $3484 \mathrm{~cm}^{-1}$ (for $v \mathrm{O}-\mathrm{H}$ stretching vibration, disappeared), $2925 \mathrm{~cm}^{-1}$ (for $v \mathrm{C}-\mathrm{H}$ stretching vibration, increased), and $1738 \mathrm{~cm}^{-1}$ (for $v \mathrm{C}-\mathrm{H}$, increased) and $1114 \mathrm{~cm}^{-1}$ (for $v$ C-O stretching vibration, increased) showed obvious changes. These absorption peak intensity changes indicated that new interaction occurred between free ILQ
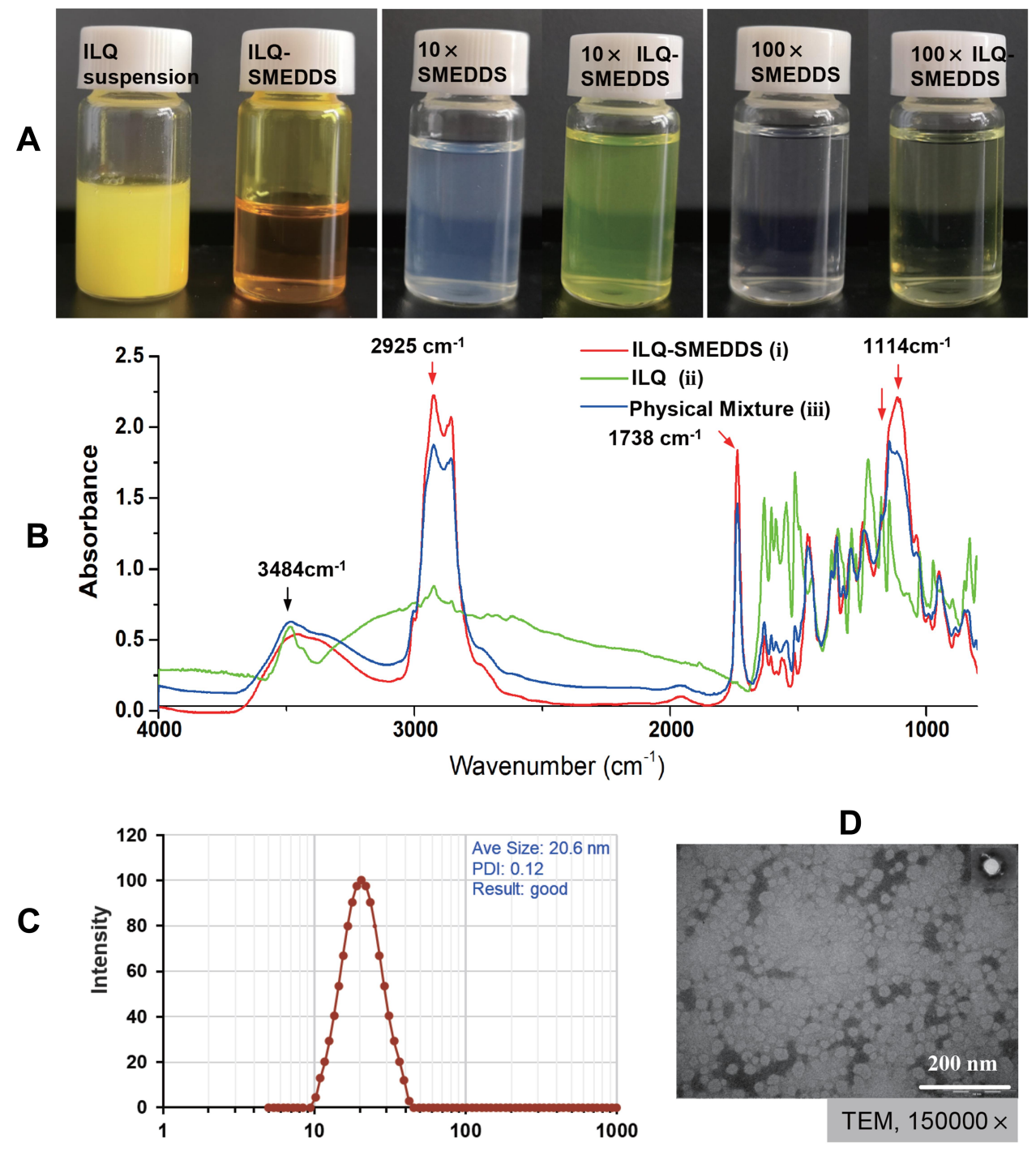

D

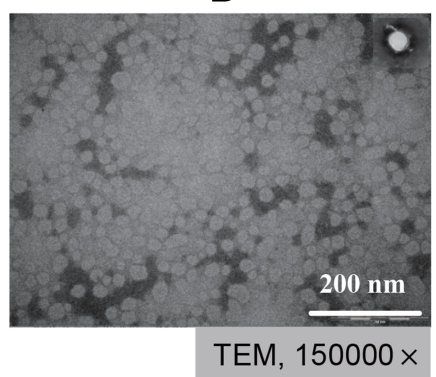

Figure 3 Physiochemistry characterization of ILQ-SMEDDS. (A) The appearance of freshly prepared ILQ suspension and ILQ-SMEDDS. (B) FTIR spectra of ILQ-SMEDDS (i), ILQ (ii), and physical mixture (iii). (C) Its globule size distribution, and (D) the TEM image of ILQ-SMEDDS (I0 times dilution, I0x). 
and SMEDDS, which could explain the above appearance changes in Figure S2. ${ }^{45}$

When drug content of the optimized ILQ-SMEDDS was $58.87 \pm 0.10 \mathrm{mg} / \mathrm{g}$, it had a small and uniform mean globule size of $20.63 \pm 1.95 \mathrm{~nm}$ (Figure 3C, with a PDI of $0.11 \pm 0.03$ ), and its zeta potential was $-12.64 \pm 2.12 \mathrm{mV}$. In addition, the TEM image (Figure 3D) of ILQ-SMEDDS showed that most of the nanoemulsion globules were spherical in shape with uniform size in the range of 16-38 nm which was consistent with the DLS results. Normally, the small globule size is very important for SMEDDS, which can promote the absorption and permeation of drugs on the intestinal membrane by providing a larger surface area. ${ }^{46}$

\section{In vitro Release Profiles and Stability of ILQ-SMEDDS}

In addition, we were also concerned about the release behavior and stability of the ILQ-SMEDDS. The release profile under different media, the robustness to dilution, the $\mathrm{pH}$ difference of the GIT and the storage stability of ILQ-SMEDDS were investigated.

The in vitro cumulative release profiles of ILQSMEDDS showed $10.54 \pm 1.82 \%$ of ILQ release in $\mathrm{pH}$ $1.2 \mathrm{HCl}$ (simulated gastric fluid) after $2 \mathrm{~h}$ and at the end of $24 \mathrm{~h}$, total $70.13 \pm 3.47 \%$ of ILQ was released in phosphate buffer $\mathrm{pH} 6.8$ (simulated intestinal fluid). ILQ-suspension, meanwhile, exhibited only $6.624 \pm 2.33 \%$ of ILQ release in $\mathrm{pH} 1.2 \mathrm{HCl}(2 \mathrm{~h})$, and total $37.25 \pm 4.09 \%$ of ILQ was released in phosphate buffer $\mathrm{pH} 6.8$ at the end of $24 \mathrm{~h}$ (Figure 4A). ILQ-SMEDDS showed a much higher dissolution rate of ILQ than ILQ-Suspension and ILQ + SMEDDS in phosphate buffer at $\mathrm{pH} 6.8$, and the dissolution rate of ILQ + SMEDDS was comparable to that of
ILQ suspension (Figure 4B), revealing that only ILQ entrapped in SMEDDS could obtain a high dissolution rate. This result was consistent with earlier studies that SMEDDS showed significantly enhanced dissolution pattern. ${ }^{30}$ This indicated that more amount of ILQ would be carried to intestine in nano-size globule and this would play a crucial role in its bioavailability enhancement via intestinal lymphatic transport. ${ }^{44,46}$ And this result was further substantiated by the in vivo pharmacokinetics and pharmacodynamics studies.

The dilution stability of optimized ILQ-SMEDDS was also observed in simulated gastric and intestinal fluid $(\mathrm{pH}$ $1.2 \mathrm{HCl}$ and $\mathrm{pH} 6.8$ phosphate buffer) (Table S2). The results showed that dilution and $\mathrm{pH}$ of the aqueous phase did not produce significant change of globule size and PDI (despite the slight increase), indicating that ILQ in the optimized formulation would be stabilized upon dilution throughout the GIT. In order to evaluate the effect of storage temperature on the stability of the formulation, its stability at $4{ }^{\circ} \mathrm{C}$ and $40^{\circ} \mathrm{C}$ for 3 months was also studied and the result was shown in Table S3. Although ILQSMEDDS is a thermodynamically stable system, it probably coalesces under $40^{\circ} \mathrm{C}$ condition for long-term storage. It can be inferred from Table S3 that ILQ-SMEDDS is better preserved at low temperature. All the above results suggested that the formulation of ILQ-SMEDDS was stable for in vivo applications.

\section{Intestinal Absorption in situ and Pharmacokinetic Study}

The perfusion study in situ was used to ascertain the potential of SMEDDS formulation for improved absorption of ILQ across the GI. As shown in Figure 5A, the AP after $2 \mathrm{~h}$ in the proximal jejunum segment was about

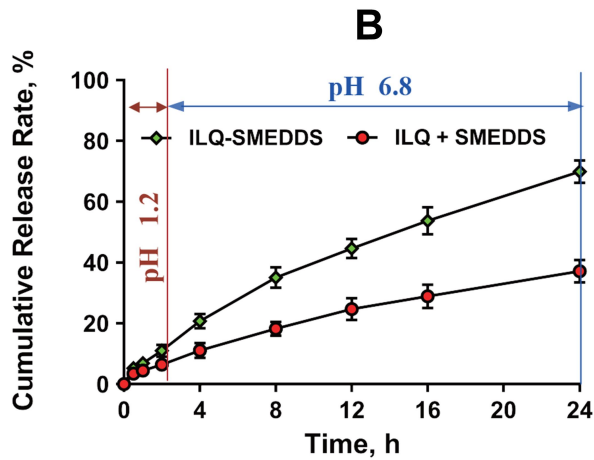

Figure 4 In vitro release profiles of ILQ from ILQ suspension and ILQ-SMEDDS (A), and ILQ + SMEDDS and ILQ-SMEDDS (B) in simulated gastric (pH I.2, for the first 2h) and intestinal $(\mathrm{pH} 6.8 \mathrm{PBS}$ for the rest $22 \mathrm{~h}$ ) fluid. 

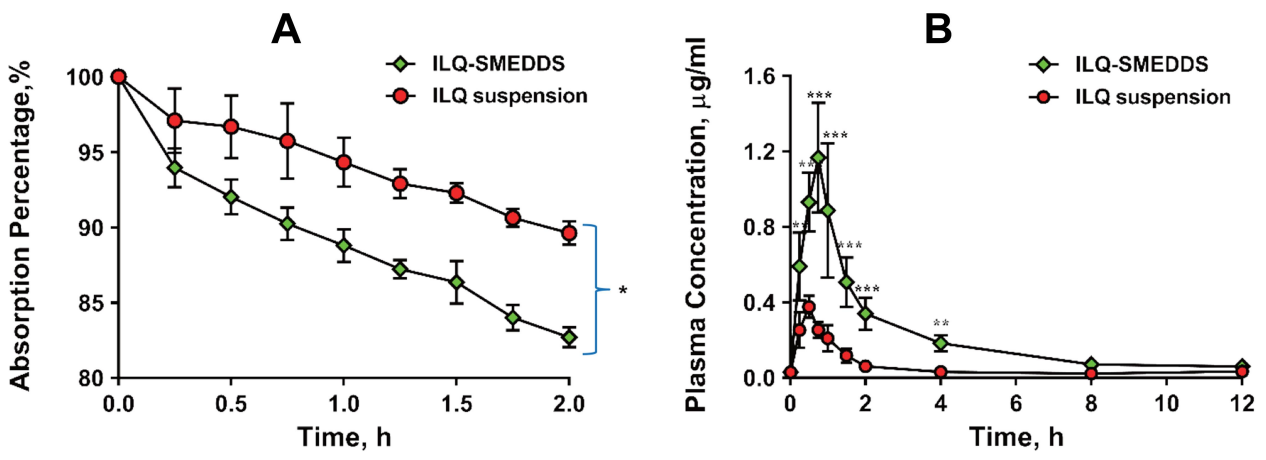

Figure 5 (A) Absorption percentage curve of ILQ suspension or ILQ-SMEDDS in rats' proximal jejunum segment after perfusing $2 \mathrm{~h}$ with an ILQ dose of $200 \mu \mathrm{gg} / \mathrm{mL}$. Length of jejunum: 12-15cm; Each value represents the mean \pm SD, ${ }^{*} p<0.05$ (Prism Mann Whitney test, $n=3$ ). (B) Mean plasma concentration-time profiles of ILQ in mice after oral administration of ILQ suspension or ILQ-SMEDDS (equivalent dose) at a dose of $35 \mathrm{mg} / \mathrm{kg}$ of ILQ. Each value represents the mean $\pm \mathrm{SD}$, *** $<0.0 \mathrm{I}$, $* * * \mathrm{p}<0.00 \mathrm{I}$. (Each time point, $n=3)$.

$10.36 \%$ and $16.45 \%$ for ILQ suspension and for ILQSMEDDS, respectively $(\mathrm{p}<0.05)$. The parameters denoting the enhancement of absorption, such as absorption rate constant $\left(\mathrm{K}_{\mathrm{a}}\right)$, appearance permeability coefficient $\left(\mathrm{P}_{\mathrm{app}}\right)$ and enhancement ratio (ER), were calculated and represented in (Table 4A). The obtained $\mathrm{K}_{\mathrm{a}}$ and $\mathrm{P}_{\text {app }}$ of ILQSMEDDS were significantly higher than that of the ILQ suspension. And the enhancement ratio (ER) was greater than 2, which indicated that there was a high potential for SMEDDS to improve the oral administration of ILQ.

A single dose of $35 \mathrm{mg} / \mathrm{kg}$ of ILQ (dissolved in 2\% Tween 80) suspension and ILQ-SMEDDS (equivalent to free ILQ) were orally administered to mice. As shown in Figure $5 \mathrm{~B}$, the maximum plasma concentration $\left(\mathrm{C}_{\max }\right)$ of ILQ was sharply elevated by 3.16 times by SMEDDS after

Table 4 (A) The Absorption Percentage (AP), The Absorption Rate Constant $\left(\mathrm{K}_{\mathrm{A}}\right)$, and the Apparent Permeability Coefficient $\left(P_{\text {app }}\right)$ and the Enhancement Ratio (ER) Were Calculated by in situ Intestinal Perfusion Method (n=3). (B) Pharmacokinetic Parameters After Oral Administration of ILQ (35 mg/kg) or ILQ-SMEDDS (Equivalent Dose) in Mice

\begin{tabular}{|c|c|c|}
\hline Items A & ILQ Suspension & ILQ-SMEDDS \\
\hline AP/\% & $10.36 \pm 1.06$ & $16.45 \pm 1.67 \pm \mid$ \\
\hline$K_{a} / h^{-1}$ & $0.059 \pm 0.009$ & $0.079 \pm 0.011$ \\
\hline$P_{\text {app }} \cdot 10^{-4} / \mathrm{h}^{-1} \cdot \mathrm{cm}^{-2}$ & $4.93 \pm 0.51$ & $10.27 \pm 0.92$ \\
\hline Items B & ILQ suspension & ILQ-SMEDDS \\
\hline$K_{e}, h^{-1}$ & $0.16 \pm 0.03$ & $0.22 \pm 0.02$ \\
\hline $\mathrm{T}_{1 / 2}, \mathrm{~h}$ & $4.48 \pm 1.16$ & $3.06 \pm 0.29$ \\
\hline $\mathrm{T}_{\max ,} \mathrm{h}$ & $0.50 \pm 0.0$ & $0.67 \pm 0.14$ \\
\hline $\mathrm{C}_{\max }, \mu \mathrm{g} \cdot \mathrm{mL}^{-1}$ & $0.37 \pm 0.12$ & $1.17 \pm 0.35^{*}$ \\
\hline $\mathrm{AUC}_{0-12}, \mu \mathrm{g} \cdot \mathrm{mL}^{-1} \mathrm{~h}$ & $0.67 \pm 0.11$ & $2.63 \pm 0.55^{* *}$ \\
\hline $\mathrm{Vz} / \mathrm{F}, \mathrm{L}$ & $257.61 \pm 55.49$ & $56.31 \pm 16.17^{* *}$ \\
\hline
\end{tabular}

Notes: ${ }^{*} p<0.05,{ }^{* *} p<0.01$. oral administration. It took some time for ILQ to be more absorbed from the intestine, so, the time to reach peak plasma concentration of $\left(\mathrm{T}_{\max }\right)$ of ILQ was delayed by about $10 \mathrm{~min}$ by SMEDDS. The pharmacokinetic parameters summarized in Table 4B were calculated using a non-compartmental analysis after extravascular input. The values of area-under-the concentration-time curve $\left(\mathrm{AUC}_{0-}\right.$ 12) of ILQ-SMEDDS were substantially higher than that of ILQ suspension. Due to its poor solubility, ILQ suspension exhibited poor bioavailability, its $\mathrm{AUC}_{0-12}$ was just $0.67 \pm$ $0.11 \mu \mathrm{g} \cdot \mathrm{h} \cdot \mathrm{mL}^{-1}$. As might be expected, the $\mathrm{AUC}_{0-12}$ of ILQ-SMEDDS was $2.63 \pm 0.55 \mu \mathrm{g} \cdot \mathrm{h} \cdot \mathrm{mL}^{-1}$, and its bioavailability was significantly increased by 3.92 times. The above results revealed that in vivo absorption of ILQ was markedly enhanced by SMEDDS, which was in line with in vitro drug release result of SMEDDS-ILQ and its improved anti-asthma effect in vivo. Hemolysis issue of Tween 80 has already attracted wide attention, and the dosage and usage of Tween- 80 are the focus of safety issues. In the present study, although the dosage of tween- 80 was a bit large, it would not cause serious hemolysis in the above maximum concentration of ILQ-SMEDDS (Figure S4).

The low bioavailability of free ILQ suspension was mainly attributed to its poor absorption, low intestinal permeability and rapid elimination. ${ }^{20}$ Although SMEDDS significantly increased the plasma concentration of ILQ, it caused little change in elimination rate $\left(\mathrm{K}_{\mathrm{e}}\right)(0.16 \pm 0.03$ vs $0.22 \pm$ 0.02). Moreover, the elimination rate of ILQ-SMEDDS was very fast, even its $t_{1 / 2}$ was a little shorter than that of free ILQ (3.06 \pm 0.29 vs $4.48 \pm 1.16)$. And further improvement of the prescription will be performed in follow-up research.

Altogether, the improvement of ILQ-SMEDDS bioavailability could be attributed to the following two factors: (i) SMEDDS formulation could keep ILQ dissolved to avoid 
determining the rate of dissolution steps. (ii) The small sphere size (less than 100nm) and lipid-based formulation of ILQ-SMEDDS would facilitate the intestinal lymph transport of ILQ, which played an important role in oral absorption of ILQ. ${ }^{37}$ (iii) By being embedded in vesicles, ILQ could offer a long time contact with the intestinal wall in vivo due to the favorable adhesiveness of SMEDDS to the mucosal surface of intestine tenue, thereby prolonging the residence time of ILQ in the systemic circulation.

\section{ILQ-SMEDDS Inhibits the Production of Eotaxin-I on HFL-I Cells}

Eotaxin-1 is a major chemoattractant ${ }^{32}$ that contributes to eosinophilic inflammation in asthma, which is a potential useful biomarker for the diagnosis and assessment of asthma severity and control. ${ }^{35}$ In our early study, we found that ILQ significantly suppressed eotaxin-1 production over $72 \mathrm{~h}$ with the second lowest IC50 (half maximal inhibitory concentration) among the ten ingredients in Glycyrrhiza uralensis. ${ }^{35}$ As shown in Figure 6A, both free ILQ and ILQSMEDDS (with equivalent dose) showed dose-dependent inhibition of eotaxin-1 production by HFL-1 cells. Blank SMEDDS could neither inhibit eotaxin-1 production nor affect cell viability (Figure 6A and B). And free ILQ suspension and ILQ-SMEDDS had no significant difference in eotaxin-1 inhibition under all dosage conditions. The IC50 of ILQ-SMEDDS was $2.66 \mu \mathrm{g} \cdot \mathrm{mL}^{-1}$ (Figure $6 \mathrm{C}$ ), showing a comparable inhibitory effect on eotaxin-1 production with that of free ILQ (1.95 $\mu \mathrm{g} \cdot \mathrm{mL}^{-1}$, Figure $6 \mathrm{D}$ ).

However, ILQ-SMEDDS showed better safety profile than free ILQ at high concentrations. Even at an equal concentration of $50 \mu \mathrm{g} / \mathrm{mL}$ (as shown in Figure 6B), the cell viability of ILQSMEDDS was more than $80 \%$, but free ILQ suspension caused nearly $50 \%$ of cell death. This was mainly because ILQ should be released from ILQ-SMEDDS before it could inhibit the production of eotaxin-1 (or cause cell death). In addition, dissolution was a very critical factor in the absorption study
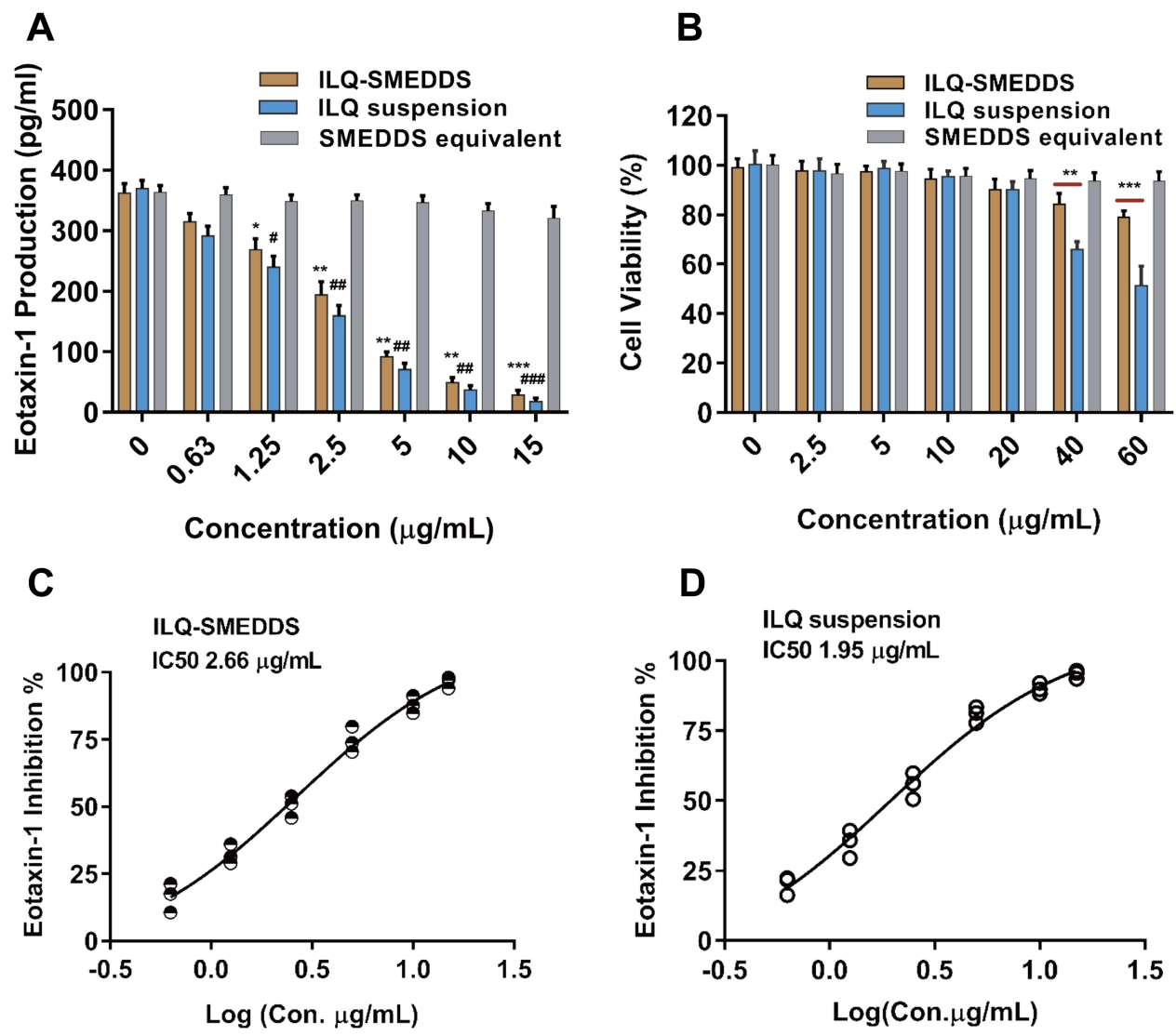

Figure 6 In vitro eotaxin-I inhibition assay on HFL-I cells. (A) Dose-dependent inhibitory effect of ILQ, ILQ-SMEDDS and blank SMEDSS (equivalent volume to ILQSMEDDS) on eotaxin-I production by HFL-I cells. Results were expressed as mean \pm SD.* or ${ }^{\#} P<0.05$; **or ${ }^{* \#} P<0.01$; ***or ${ }^{* \# \#<0.00 I}$ ( $n=3$ ), compared to the negative control. (B) Cell viability of HFL-I cells at various concentrations of ILQ suspension, ILQ-SMEDDS and blank SMEDDS. **p < 0.0I, ***p < 0.00I ( $=3$ ). (C and $\mathbf{D}$ ) Percentage of eotaxin-I inhibition vs $\log (\mathrm{x})$ ILQ-SMEDDS (C) and ILQ (D) concentration curve. HFL-I cells $\left(2 \times 10^{5}\right.$ cells $\left./ \mathrm{mL}\right)$ were cultured with ILQ, ILQ-SMEDD and blank SMEDDS at concentrations $0.63,1.25,2.5,5,10$ and $15 \mu \mathrm{g} / \mathrm{mL}$ for 3 days. The supernatants were harvested and eotaxin-I levels were measured by enzyme-linked immunosorbent assay. 
in vivo, but dissolution should not be a rate-limiting step at the cellular level. The negative surface charge carried by ILQSMEDDS might reduce the rate of cell uptake, resulting in a slight increase in its IC50 and obvious decreased toxicity. ${ }^{28,47}$ For in vivo application of nano-drug delivery systems, it is important to have a neutral or negative charge, which can reduce non-specific interactions and thereby reduce toxic and side effects. $^{48}$

Due to its inhibition on cell proliferation and viability in many types of cancer cells, ILQ also has potential as an anticancer agent. ${ }^{18,49}$ In the present study, the effective concentration of ILQ to inhibit the eotaxin-1 production was much lower than the effective concentration to inhibit cell proliferation, and in a wide range, ILQ-SMEDDS had almost no effect on the proliferation and viability of HFL-1 cells. Therefore, ILQ-SMEDDS is a very safe anti-allergic agent.

\section{The Anti-Asthma Effects of ILQ-SMEDDS} in vivo

ILQ-SMEDDS Reduced the Levels of OVA-slgE in Peripheral Blood and IL4, IL-5 in BALF, and Increased the Levels of IFN- $\gamma$

OVA-induced allergic asthma murine model, which greatly mimics the characteristic asthma symptoms and pathological changes of asthma, was used to evaluate anti-asthma effect of ILQ-SMEDDS. Compared with the naïve mice, the model mice showed slow movement, poor hair gloss and loose stools after the second OVA challenge, and some of them also had red and swollen nose. These physiological conditions and asthma symptoms were gradually improved following the treatment of ILQ-SMEDDS or free ILQ. Asthma has long been regarded as a typical $\mathrm{T}$ helper 2 (Th2) cell-mediated disease, and this process is driven by IL-4 dependent class switching in B cell, resulting in a significant increase in the production of $\operatorname{IgE} .^{50} \mathrm{As}$ shown in Figure 7A and B and $\mathrm{E}$ and $\mathrm{F}$, the levels of OVA-sIgE, IL-4 and IL5 increased significantly in the sham group. After four weeks of treatment, the OVA-sIgE level of all treatment groups was accordingly significantly reduced. Especially in the high-dose ILQ-SMEDDS group, the inhibition rate reached $67.4 \%$, significantly higher than that of the ILQ group (53.3\%) and slightly higher than that of the DEX group (63.6\%) (Figure 7A). In addition, two days after the 4th and 5th OVA challenge, the OVA-sIgE levels of all ILQ treatment groups increased slightly. However, the sham group and the DEX group showed a significant increase, and even the DEX group increased by 2.41 times $(\mathrm{p}<0.01)$ (Figure $7 \mathrm{~B})$. The results of cytokines in the BALF were consistent with the results of sIgE above. As shown in Figure $7 \mathrm{C}-\mathrm{F}$, the DEX group and all ILQ groups could significantly suppress the production of Th2-type cytokines, including IL-4 and IL-5, which were found greatly down-regulated compared to the sham group $(\mathrm{p}<0.01)$. The high-dose ILQ-SMEDDS group
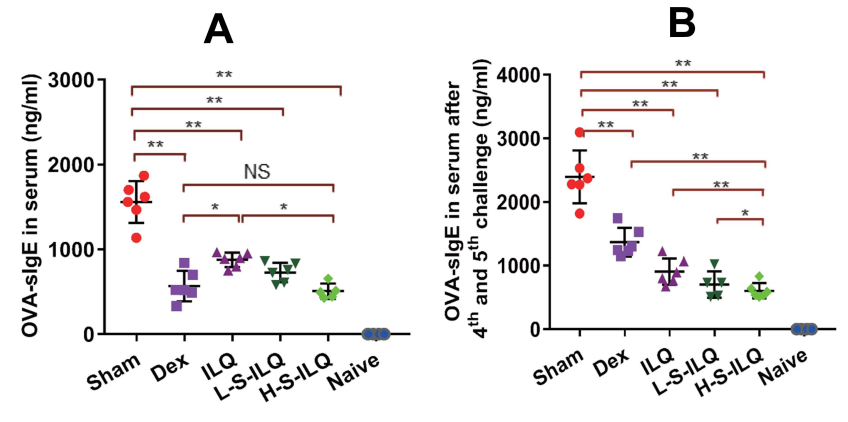

D

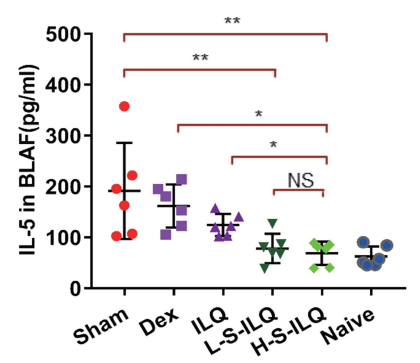

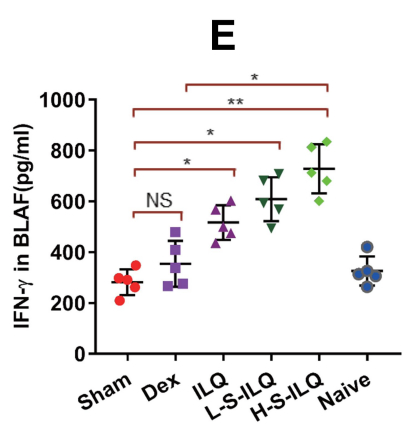

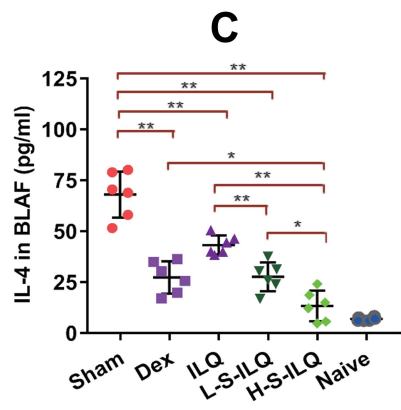

$\mathbf{F}$

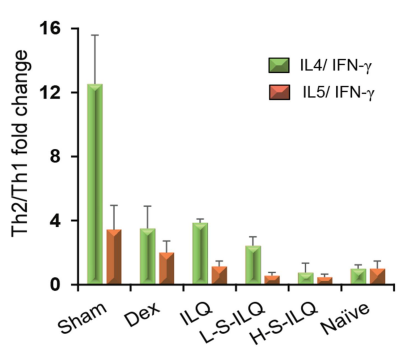

Figure 7 Levels of OVA-slgE in peripheral blood and cytokines of IL4, IL-5, and IFN- $\gamma$ in BALF in the six groups ( $n=6)$. Levels of OVA-slgE at day 63 ((A) before 4th OVA intratracheally challenge) and at day 66 ((B) 2 days after 5th OVA intratracheally challenge) in peripheral blood. Levels of IL4 (C), IL5 (D) and IFN- $\gamma$ (E) in BALF. (F) Th2/Th I cytokines fold change in the six groups. The data shown are the mean \pm SD. ${ }^{*} p<0.05$, ${ }^{*} p<0.01$, NS, no significant difference respectively. 
showed the most effective inhibition of Th2 cytokines, which was significantly higher than that of DEX $(p<0.05)$ and free ILQ $(\mathrm{p}<0.01)$ treatment groups (Figure $7 \mathrm{C}$ and D). In addition, unlike the DEX group, the ILQ-SMEDDS group also showed a significantly elevated IFN- $\gamma$ level (Figure 7E). Acting as an anti-inflammatory mediator, IFN- $\gamma$ is considered to be one of the most critical cytokines and is involved in the alleviation of Th2 inflammation. ${ }^{50,51}$ These results demonstrated that ILQ-SMEDDS treatment could more effectively ameliorate inflammation associated with asthma than DEX or free ILQ treatment.

\section{ILQ-SMEDDS Markedly Suppressed the Inflammatory Cell Counts in BALF}

Allergic asthma is defined as chronic reversible inflammatory airway disease, ${ }^{1}$ which is characterized by allergy, inflammation, airway hyperreactivity and air remodeling, and the number of immune cells increased in the airway. ${ }^{8,52}$ As shown in Figure 8A, total cells and the percentage of eosinophils in


Figure 8 The inflammatory cell counts in BALF and lung histologic changes in the six groups $(n=6)$. (A) The inflammatory cell counts in BALF of each group. ILQ-SMEDDS treatment apparently decreased the inflammatory cell counts in BALF of OVA-induced asthma model. The data shown are the mean \pm SD. $* P<0.05$, ** $<0.0$ I. (B and $\mathbf{C}$ ) Lungs from the indicated mice sectioned and stained with Hematoxylin-Eosin stain ((B) H\&E, $\times 400)$ and Periodic Acid-Schiff stain ((C) PAS, $\times 400)$. (i: Naïve group, PBS treatment; ii: Sham group, OVA i.p. and i.t. iii: Dex-treated mice $(0.5 \mathrm{mg} / \mathrm{kg})$ with OVA i.p. and i.t. iv: ILQ-treated mice $(10 \mathrm{mg} / \mathrm{kg})$ with OVA i.p. and i.t. v, vi: ILQ-SMEDDStreated mice (10, $20 \mathrm{mg} / \mathrm{kg})$ with OVA i.p. and i.t.). 
BALF in the sham group were dramatically increased compared to that in the naïve group. Both the ILQ and ILQSMEDDS -treated mice showed markedly lower inflammatory cells. There was no significant difference between $20 \mathrm{mg} / \mathrm{kg}$ dose of ILQ-SMEDDS group and $0.5 \mathrm{mg} / \mathrm{kg}$ of DEX group in the number of eosinophils. As expected, ILQ-SMEDDS (with equivalent dose) showed to be more effective than ILQ in reducing the number of inflammatory cells and eosinophils ( $p$ $<0.05$ ), which could be further verified by the results of the histologic analysis. These pathological changes in lung tissue were assessed by hematoxylin and eosin (HE) staining. Compared to that of the sham mice (Figure $8 \mathrm{~B}$ and $\mathrm{C}$ ), the lung inflammation (such as smooth muscle hypertropia, bronchial congestion and inflammatory cell infiltration, etc.) of mice in all four treatment groups was significantly relieved, especially in the H-ILQ-SMEDDS (high dose, Figure 8Bvi and Cvi) group.

Studies have shown that the accumulation of eosinophils correlated well with the levels of eotaxin-1 measured in the lung tissue of allergic asthma model mice. ${ }^{53}$ In the eotaxin- 1 in vitro inhibition study, the IC50 of ILQ was lower than that of ILQ-SMEDDS. However, ILQ-SMEDDS with the equivalent dose showed more potent inhibition of eosinophils production than free ILQ suspension, which could be attributed to the increased absorption of ILQ in vivo by SMEDDS.

ILQ, a single component of ASHMI, also showed the same anti-asthma mechanism, which significantly reduced Th2 cytokines and slightly increased the production of Th1 cytokines, thereby regulating the Th2/Th1 balance, ${ }^{9}$ and ILQ-SMEDDS (high dose) group showed the most effective regulation of Th2/ Th1 balance (Figure 7F). Lin et al divided asthma-related cytokines into three stages, firstly the epithelial environment stage, secondly the Th2 polarization stage, and finally the tissue injury stage, in which ILQ is mainly aimed at the second stage and inhibits the secretion of inflammatory factors by Th2 cells. ${ }^{54}$ The effects of ILQ on airway inflammation in the murine asthma model have not been previously reported. ASHMI, like most traditional Chinese medicines, has a typical problem of poor patient compliance due to its large dose and difficulty in dissolution, so we tried to prepare the ILQSMEDDS to improve compliance of asthma patients. Whereas low dose of ILQ-SMEDDS group (10mg/kg) had better IL-4 suppression effect than the ILQ suspension group $(20 \mathrm{mg} / \mathrm{kg})(\mathrm{p}<0.01)$, and there was no significant difference in the concentrations of OVA-sIgE, IL-5 and IFN- $\gamma$ between the two groups. The results indicated that the ILQ-SMEDDS<smiles>O=C(/C=C/c1ccc(O)cc1)c1ccc(O)cc1O</smiles>
Isoliquiritigenin (ILQ)

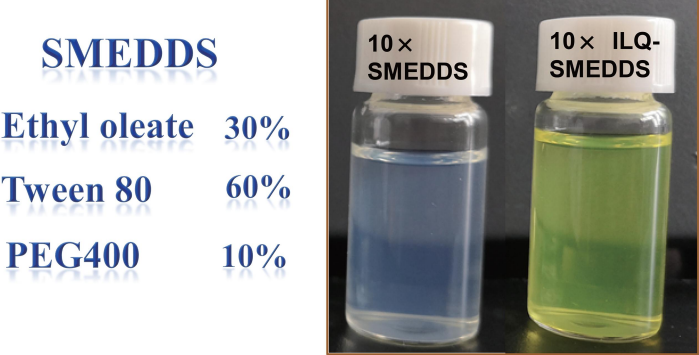

ILQ-SMEDDS

O / W

Small Size

$20.63 \pm 1.95 \mathrm{~nm}$

High drug content Max $7.8 \%$
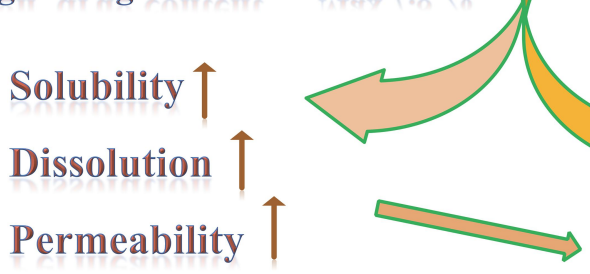

Improved bioavailability

Enhanced anti-asthma efficacy

Scheme I Experimental design and results for the development of ILQ-SMEDDS. 
preparation had succeeded the objective of reducing the effective therapeutic dose.

In general, ILQ-SMEDDS treatment could significantly relieve asthma symptoms and lung morphological changes than ILQ treatment, which could be mainly attributed to the promotion of oral absorption of ILQ by SMEDDS.

\section{Conclusion}

In the present study, ILQ, an important component of ASHMI, was used as a model agent for the development of oral SMEDDS. The optimized SMEDDS consisted of $30 \%$ ethyl oleate (oil phase), 60\% Tween 80 (surfactant), and 10\% PEG400 (co-surfactant), with satisfactory biophysical properties, including small droplet size, appropriate negative zeta potential, high drug content and good stability. And these favorable properties of ILQ-SMEDDS led to improved bioavailability and anti-asthma activity of ILQ (Scheme 1). The intestinal absorption, pharmacokinetics and anti-asthma effect in vivo studies indicated that SMEDDS could significantly enhance the oral bioavailability of ILQ, and displayed preferable anti-asthma activities in an ovalbumin-induced asthma model. In a word, the optimized SMEDDS formula could reduce the dose of ILQ by improving its anti-asthma effect. This study provides a new promising pharmaceutical candidate for allergic asthma treatment.

\section{Acknowledgment}

This work was supported by the grants including the Key Scientific Research Projects of Universities in Henan Province (20A350005), and Henan Outstanding Foreign Scientist Project (GZS2019006). We thank Mr. Henry Ehrlich for checking our manuscript for language and grammar.

Equal corresponding authors: Xiu-Min Li and Mingsan Miao.

\section{Disclosure}

Mingzhuo Cao reports grants from Key Scientific Research Projects of Universities in Henan Province (20A350005), grants from Henan Outstanding Foreign Scientist Project (GZS2019006), grants from Henan university of Chinese Medicine.

Xiu-Min Li reports grants from $\mathrm{NIH}$, grants from the Parker Foundation, grants from Henan University of Chinese Medicine, during the conduct of the study; grants from Research and Education (FARE), grants from Winston Wolkoff Integrative Medicine Fund for Allergies and Wellness, personal fees from Johnson \& Johnson Pharmaceutical Research \& Development, L.L.C., personal fees from Bayer Global Health LLC, received royalty from UpToDate, outside the submitted work; in addition, Professor Xiu-Min Li has a patent US patent PCT/US05/ 008417 (FAHF-2) issued, a patent PCT 14/875,772 (XPP) issued, a patent PCT/US2014/012306 (S. Flavescens) issued, a patent PCT/US14/68396 (WL) issued, a patent PCT/US2017/056822 (nanoBBR) pending; and Integrative Health and Acupuncture $\mathrm{PC}$, founder, received practice compensation; and is a member of Herbs Springs, LLC, Health Freedom LLC, and General Nutraceutical Technology.

The aforementioned authors report no other potential conflicts of interest; no potential conflicts of interest were reported by the other authors.

\section{References}

1. Zellweger F, Eggel A. IgE-associated allergic disorders: recent advances in etiology, diagnosis, and treatment. Allergy. 2016;71(12): 1652-1661. doi:10.1111/all.13059

2. Liu C, Weir D, Busse P, et al. The flavonoid 7,4'-dihydroxyflavone inhibits MUC5AC gene expression, production, and secretion via regulation of NF-кB, STAT6, and HDAC2. Phytother Res. 2015;29 (6):925-932. doi:10.1002/ptr.5334

3. Bourdin A, Adcock I, Berger P, et al. How can we minimise the use of regular oral corticosteroids in asthma? Eur Respir Rev. 2020;29 (155):190085. doi:10.1183/16000617.0085-2019

4. Huntley A, Ernst E. Herbal medicines for asthma: a systematic review. Thorax. 2000;55(11):925-929. doi:10.1136/thorax.55.11.925

5. Zhou W, Chen Z, Li W, et al. Systems pharmacology uncovers the mechanisms of anti-asthma herbal medicine intervention (ASHMI) for the prevention of asthma. J Funct Foods. 2019;52:611-619. doi:10.1016/j. jff.2018.11.048

6. Busse PJ, Wen M, Srivastava K, et al. Safety, tolerability and beneficial immunological responses of complementary ashmi therapy to inhaled corticosteroids therapy in children with persistent allergic asthma with or without allergic rhinitis. $J$ Allergy Clin Immunol. 2010;125(2):AB199. doi:10.1016/j.jaci.2009.12.779

7. Wen MC, Wei CH, Hu ZQ, et al. Efficacy and tolerability of antiasthma herbal medicine intervention in adult patients with moderatesevere allergic asthma. J Allergy Clin Immunol. 2005;116(3):517524. doi:10.1016/j.jaci.2005.05.029

8. Srivastava K, Zhang T, Yang N, Sampson H, Li XM. Anti-asthma simplified herbal medicine intervention-induced long-lasting tolerance to allergen exposure in an asthma model is interferon-gamma, but not transforming growth factor-beta dependent. Clin Exp Allergy. 2010;40(11):1678-1688. doi:10.1111/j.1365-2222.2010.03 545.x

9. Jayaprakasam B, Yang N, Wen MC, et al. Constituents of the anti-asthma herbal formula ASHMI(TM) synergistically inhibit IL-4 and IL-5 secretion by murine Th2 memory cells, and eotaxin by human lung fibroblasts in vitro. J Integr Med. 2013;11(3):195-205. doi:10.3736/jintegrmed20 13029

10. Yang N, Patil S, Zhuge J, et al. Glycyrrhiza uralensis flavonoids present in anti-asthma formula, ASHMI, inhibit memory Th2 responses in vitro and in vivo. Phytother Res. 2013;27(9):13811391. doi:10.1002/ptr.4862 
11. Kelly-Pieper K, Patil SP, Busse P, et al. Safety and tolerability of an antiasthma herbal formula (ASHMI (TM)) in adult subjects with asthma: a randomized, double-blinded, placebo-controlled, doseescalation phase i study. J Altern Complem Med. 2009;15(7):735743. doi:10.1089/acm.2008.0543

12. Bolleddula J. Synergistic modulation of eotaxin and IL-4 secretion by constituents of an anti-asthma herbal formula (ashmi) in vitro. $J$ Allergy Clin Immunol. 2007;119(1):S172. doi:10.1016/j.jaci.2006.12.035

13. Yang N, Zhu-ge J, Zhang W, et al. Flavonoids from Gan-Cao (radix glycerrhizae) inhibit Th2 memory cell cytokine production. $J$ Allergy Clin Immunol. 2010;125(2):AB198-AB.

14. Park CG, Lee AY, Lee JH, et al. Biological activities of licorice f1 lines and content analysis of phytochemical constituents. Nat Prod Sci. 2014;20(3):137-145.

15. Yu D, Liu X, Zhang G, Ming Z, Wang T. Isoliquiritigenin inhibits cigarette smoke-induced COPD by attenuating inflammation and oxidative stress via the regulation of the Nrf2 and NF- $\mathrm{KB}$ signaling pathways. Front Pharmacol. 2018;9:1001. doi:10.3389/fphar.2018. 01001

16. Funakoshi-Tago M, Okamoto K, Izumi R, et al. Anti-inflammatory activity of flavonoids in Nepalese propolis is attributed to inhibition of the IL-33 signaling pathway. Int Immunopharmacol. 2015;25 (1):189-198. doi:10.1016/j.intimp.2015.01.012

17. Traboulsi H, Cloutier A, Boyapelly K, et al. The flavonoid isoliquiritigenin reduces lung inflammation and mouse morbidity during influenza virus infection. Antimicrob Agents Chemother. 2015;59 (10):6317-6327. doi:10.1128/AAC.01098-15

18. Zhang XY, Qiao H, Ni JM, Shi YB, Qiang Y. Preparation of isoliquiritigenin-loaded nanostructured lipid carrier and the in vivo evaluation in tumor-bearing mice. Eur J Pharm Sci. 2013;49 (3):411-422. doi:10.1016/j.ejps.2013.04.020

19. Yadav VR, Prasad S, Sung B, Aggarwal BB. The role of chalcones in suppression of NF-kB-mediated inflammation and cancer. Int Immunopharmacol. 2011;11(3):295-309. doi:10.1016/j.intimp.2010. 12.006

20. Lee YK, Chin Y-W, Bae J-K, Seo JS, Choi YH. Pharmacokinetics of isoliquiritigenin and its metabolites in rats: low bioavailability is primarily due to the hepatic and intestinal metabolism. Planta Med. 2013;79(17):1656-1665. doi:10.1055/s-0033-1350924

21. Liu J, Wang Q, Adu-Frimpong M, et al. Preparation, in vitro and in vivo evaluation of isoliquiritigenin-loaded TPGS modified proliposomes. Int J Pharm. 2019;563:53-62. doi:10.1016/j.ijpharm.2019.03.034

22. Gao F, Zhang J, Fu C, et al. iRGD-modified lipid-polymer hybrid nanoparticles loaded with isoliquiritigenin to enhance anti-breast cancer effect and tumor-targeting ability. Int $J$ Nanomedicine. 2017;12:4147-4162. doi:10.2147/IJN.S134148

23. Sun X, Zhang J, Wang Z, et al. Licorice isoliquiritigenin-encapsulated mesoporous silica nanoparticles for osteoclast inhibition and bone loss prevention. Theranostics. 2019;9(18):5183-5199. doi:10.71 50/thno. 33376

24. Noh GY, Suh JY, Park SN. Ceramide-based nanostructured lipid carriers for transdermal delivery of isoliquiritigenin: development, physicochemical characterization, and in vitro skin permeation studies. Korean J Chem Eng. 2017;34(2):400-406. doi:10.1007/s11814016-0267-3

25. Kong BJ, Kim A, Park SN. Properties and in vitro drug release of hyaluronic acid-hydroxyethyl cellulose hydrogels for transdermal delivery of isoliquiritigenin. Carbohydr Polym. 2016;147:473-481. doi:10.1016/j.carbpol.2016.04.021

26. Xie Y-J, Wang Q-L, Adu-Frimpong M, et al. Preparation and evaluation of isoliquiritigenin-loaded F127/P123 polymeric micelles. Drug Dev Ind Pharm. 2019;45(8):1224-1232. doi:10.1080/03639045.2019.1574812

27. Li B, Liu B, Li J, Xiao H, Wang J, Liang G. Experimental and theoretical investigations on the supermolecular structure of isoliquiritigenin and 6-O- $\alpha$-D-maltosyl- $\beta$-cyclodextrin inclusion complex. Int J Mol Sci. 2015;16(8):17999-18017. doi:10.3390/ijms160817999
28. Dokania S, Joshi AK. Self-microemulsifying drug delivery system (SMEDDS)-challenges and road ahead. Drug Deliv. 2015;22(6):675690. doi:10.3109/10717544.2014.896058

29. Sawatdee S, Atipairin A, Sae Yoon A, Srichana T, Changsan N, Suwandecha T. Formulation development of albendazole-loaded self-microemulsifying chewable tablets to enhance dissolution and bioavailability. Pharmaceutics. 2019;11(3):143. doi:10.3390/ pharmaceutics 11030134

30. Na YG, Byeon JJ, Wang M, et al. Strategic approach to developing a self-microemulsifying drug delivery system to enhance antiplatelet activity and bioavailability of ticagrelor. Int $J$ Nanomedicine. 2019;14:1193-1212. doi:10.2147/IJN.S190426

31. Chandrakar A, Sahu B, Sahu H, Dewangan J, Alexander A. Review on the formulation considerations needed to produce a stable self micro emulsifying drug delivery system (SMEDDS). Res J Pharm Technol. 2017;10(5):1563. doi:10.5958/0974-360X.2017.00275.X

32. Jayaprakasam B, Doddaga S, Wang R, Holmes D, Goldfarb J, Li XM. Licorice flavonoids inhibit eotaxin-1 secretion by human fetal lung fibroblasts in vitro. J Agric Food Chem. 2009;57(3):820-825. doi: $10.1021 / \mathrm{jf} 802601 \mathrm{j}$

33. Visetvichaporn V, Kim KH, Jung K, Cho YS, Kim DD. Formulation of self-microemulsifying drug delivery system (SMEDDS) by D-optimal mixture design to enhance the oral bioavailability of a new cathepsin K inhibitor (HL235). Int J Pharm. 2020;573:118772. doi:10.1016/j.ijpharm.2019.118772

34. Xie M, Wu J, Ji L, et al. Development of triptolide self-microemulsifying drug delivery system and its anti-tumor effect on gastric cancer xenografts. Front Oncol. 2019;9:978. doi:10.3389/fonc.20 19.00978

35. Liu C, Yang N, Chen X, et al. The flavonoid 7,4'-dihydroxyflavone prevents dexamethasone paradoxical adverse effect on eotaxin production by human fibroblasts. Phytother Res. 2017;31(3):449-458. doi:10.1002/ptr.5767

36. Zhang X, Qiao H, Zhang T, Shi Y, Ni J. Enhancement of gastrointestinal absorption of isoliquiritigenin by nanostructured lipid carrier. Adv Powder Technol. 2014;25(3):1060-1068. doi:10.1016/j. apt.2014.02.012

37. Li H, Zhao X, Ma Y, Zhai G, Li L, Lou H. Enhancement of gastrointestinal absorption of quercetin by solid lipid nanoparticles. $J$ Control Release. 2009;133(3):238-244. doi:10.1016/j.jconrel.2008.10.002

38. Lopez-Exposito I, Srivastava KD, Birmingham N, Castillo A, Miller RL, Li XM. Maternal antiasthma simplified herbal medicine intervention therapy prevents airway inflammation and modulates pulmonary innate immune responses in young offspring mice. Ann Allergy Asthma Immunol. 2015;114(1):43-51 e1. doi:10.1016/j.anai.2014.10.018

39. Zhang T, Srivastava K, Wen MC, et al. Pharmacology and immunological actions of a herbal medicine ASHMI on allergic asthma. Phytother Res. 2010;24(7):1047-1055. doi:10.1002/ptr.3077

40. Busse PJ, Zhang TF, Srivastava K, Schofield B, Li XM. Effect of ageing on pulmonary inflammation, airway hyperresponsiveness and $\mathrm{T}$ and $\mathrm{B}$ cell responses in antigen-sensitized and -challenged mice. Clin Exp Allergy. 2007;37(9):1392-1403. doi:10.1111/j.13652222.2007.02775.x

41. Xiong Y, Zou Y, Chen L, Xu Y, Wang S. Development and in vivo evaluation of ziyuglycoside I-loaded self-microemulsifying formulation for activity of increasing leukocyte. AAPS PharmSciTech. 2019;20(3):101. doi:10.1208/s12249-019-1313-3

42. Zhang K, Wang Q, Yang Q, et al. Enhancement of oral bioavailability and anti-hyperuricemic activity of isoliquiritigenin via self-microemulsifying drug delivery system. AAPS PharmSciTech. 2019;20 (5):218. doi:10.1208/s12249-019-1421-0

43. Sermkaew N, Plyduang T. Self-microemulsifying drug delivery systems of Moringa oleifera extract for enhanced dissolution of kaempferol and quercetin. Acta pharmaceutica. 2020;70(1):77-88. doi:10.2478/acph-2020-0012 
44. Patel MH, Sawant KK. Self microemulsifying drug delivery system of lurasidone hydrochloride for enhanced oral bioavailability by lymphatic targeting: in vitro, Caco-2 cell line and in vivo evaluation. Eur J Pharm Sci. 2019;138:105027. doi:10.1016/j.ejps.2019.105027

45. Lilly CM, Nakamura H, Kesselman H, et al. Expression of eotaxin by human lung epithelial cells: induction by cytokines and inhibition by glucocorticoids. J Clin Invest. 1997;99(7):1767-1773. doi:10.1172/ JCI119341

46. Kollipara S, Gandhi RK. Pharmacokinetic aspects and in vitro-in vivo correlation potential for lipid-based formulations. Acta Pharm Sin B. 2014;4(5):333-349. doi:10.1016/j.apsb.2014.09.001

47. Sun Q, Zhou Z, Qiu N, Shen Y. Rational design of cancer nanomedicine: nanoproperty integration and synchronization. Adv Mater. 2017;29(14):1606628. doi:10.1002/adma.201606628

48. Lopes RC, Silvestre OF, Faria AR, et al. Surface charge tunable catanionic vesicles based on serine-derived surfactants as efficient nanocarriers for the delivery of the anticancer drug doxorubicin. Nanoscale. 2019;11(13):5932-5941. doi:10.1039/C8NR06346J

49. Kwon GT, Cho HJ, Chung W-Y, Park -K-K, Moon A, Park JHY. Isoliquiritigenin inhibits migration and invasion of prostate cancer cells: possible mediation by decreased JNK/AP-1 signaling. J Nutr Biochem. 2009;20(9):663-676. doi:10.1016/j.jnutbio.2008.06.005
50. Lambrecht BN, Hammad H, Fahy JV. The cytokines of asthma. Immunity. 2019;50(4):975-991. doi:10.1016/j.immuni.2019.03. 018

51. Sur S, Wild JS, Choudhury BK, Sur N, Alam R, Klinman DM. Long term prevention of allergic lung inflammation in a mouse model of asthma by CpG oligodeoxynucleotides. J Immunol. 1999;162(10): 6284-6293.

52. Cohn L, Elias JA, Chupp GL. Asthma: mechanisms of disease persistence and progression. Annu Rev Immunol. 2004;22:789-815. doi:10.1146/annurev.immunol.22.012703.104716

53. Conroy DM, Humbles AA, Rankin SM, et al. The role of the eosinophil-selective chemokine, eotaxin, in allergic and non-allergic airways inflammation. Mem Inst Oswaldo Cruz. 1997;92(Suppl. II):183-191. doi:10.1590/S0074-02761997000800024

54. Lin SC, Shi LS, Ye YL. Advanced molecular knowledge of therapeutic drugs and natural products focusing on inflammatory cytokines in asthma. Cells. 2019;8(7):8070685. doi:10.3390/ cells 8070685
International Journal of Nanomedicine

\section{Publish your work in this journal}

The International Journal of Nanomedicine is an international, peerreviewed journal focusing on the application of nanotechnology in diagnostics, therapeutics, and drug delivery systems throughout the biomedical field. This journal is indexed on PubMed Central, MedLine, CAS, SciSearch ${ }^{\circledR}$, Current Contents ${ }^{\circledR} /$ Clinical Medicine,
Dovepress

Journal Citation Reports/Science Edition, EMBase, Scopus and the Elsevier Bibliographic databases. The manuscript management system is completely online and includes a very quick and fair peer-review system, which is all easy to use. Visit http://www.dovepress.com/ testimonials.php to read real quotes from published authors. 